\title{
Primarily Outcome of Laparoscopic Hysterectomy for Early-Stage Malignant Gynecological Cancer of Unselected Cases in Five Years
}

\author{
Juan Qin 1*, Guolin Song2*, Juntao Wang1, Anwei Lu ${ }^{1 \#}$ \\ ${ }^{1}$ Department of Obstetrics and Gynecology, MCH of Guiyang, Guiyang, China \\ ${ }^{2}$ ICU, 2nd Affiliated Hospital, Guizhou College of Traditional Chinese Medicine, Guiyang, China \\ Email: ${ }^{*}$ ant000999@163.com
}

Received 2 November 2014; revised 29 November 2014; accepted 8 December 2014

Copyright (C 2014 by authors and Scientific Research Publishing Inc.

This work is licensed under the Creative Commons Attribution International License (CC BY). http://creativecommons.org/licenses/by/4.0/

cc) (i) 0 pen Access

\section{Abstract}

Objective: To investigate the feasibility and safety of laparoscopic hysterectomy (LH) in earlystage malignant gynecological cancer. Methods: Data from patients who underwent surgical management for early-stage gynecological cancer between 2009 and 2014 were retrospectively reviewed. Each woman gave her informed consent to be included into the study, which was previously approved by the local ethics committee and Institutional Review Board. Inclusion Criteria: All patients presented with stage I or II disease, and underwent comprehensive staging surgery consisting of hysterectomy or radical hysterectomy, with or without bilateral salpingo-oophorectomy, with or without para-aortic lymphadenectomy, with or without omentectomy, and peritoneal cytology. Results: 345 patients who underwent laparoscopic surgery (201 cervical cancer cases, 110 endometrial cancer cases and 34 ovarian cancer cases) were identified. Surgery for none of the patients was converted from laparoscopy to laparotomy. The median patient age for early-stage of gynecological cancer was 48 years (range, 29 - 71 years). 87 (25.22\%) of whom were elderly ( $>60$ years); $98(28.41 \%)$ were obese $\left(>30 \mathrm{~kg} / \mathrm{m}^{2}\right) ; 164(62.96 \%)$ were postmenopausal; $103(29.86 \%)$ had undergone previous abdominal surgery; 96 (25\%) had a history of medical disease. The median operative time and estimated blood loss were 3.5 hours (range, 2.5 - 5.5 hour) and $80 \mathrm{~mL}(20-200 \mathrm{~mL})$, respectively. Intra-operative and postoperative complications occurred in $6(1.74 \%)$ and $34(9.86 \%)$. None of the patients occurred death. The interval to bowel movement and indwelling catheter were 3 days (range, 1 - 5 days) and 7 days (range, 5 - 11 days). The median postoperative hospital stay was 10 days (range, 6 - 18 days). The mean operating time and hospital days for cervical cancer was shorter; the estimated blood loss was lower; and the peri-

\footnotetext{
*These two authors have the same contribution to the paper.

\#Corresponding author.
}

How to cite this paper: Qin, J., Song, G.L., Wang, J.T. and Lu, A.W. (2014) Primarily Outcome of Laparoscopic Hysterectomy for Early-Stage Malignant Gynecological Cancer of Unselected Cases in Five Years. International Journal of Clinical Medicine, 5, 1345-1351. http://dx.doi.org/10.4236/ijcm.2014.521172 
operative complications were lower in the second stage (July 2012-May 2014) than in the first three years (May 2009-June 2012) in our department $(p<0.05)$. Conclusion: Based on the data described in our center, laparoscopic surgery seems to be adequate and feasible for the treatment of early-stage gynecological cancer in terms of the surgical outcomes and safety.

\section{Keywords}

\section{Clinical Outcome, Laparoscopic Hysterectomy, Gynecological Cancer}

\section{Introduction}

Cervical cancer, ovarian cancer and endometrial cancer remain a major health problem for women worldwide. Although the therapeutic efficacy of radical hysterectomy and radiation therapy is equivalent, patients with earlystage cancer undergo surgery because this procedure is associated with superior quality of life.

Laparoscopic surgery is considered the gold standard for the treatment of benign masses [1]. Although minimally invasive surgical techniques have improved over the last few years and laparoscopic surgery was broadly applied in gynecologic surgery [2] [3], many physicians debated the application of laparoscopic surgery for gynecological cancer.

Recently, laparoscopic surgery has been proposed as a minimally invasive therapy with comparable results to laparotomy in terms of blood loss, transfusion rate, recovery, and hospital stay [4] [5].

However, controversy remains concerning on minimized appliance owing to technical difficulty, long learning curve, and longer operative time [4] [5]. Certainly, complication and difficulty of laparoscopic are related with previous abdominal surgery, age and obesity.

Currently, our practice is to collect the data of cases with early-stage performed laparoscopic surgery within five years, and the aim of this study is to examine the feasibility of LAP in these patients, regardless of age, body mass index, prior abdominal surgery.

\section{Methods}

In our institution, there is no clear indication for laparoscopic surgery in cervical cancer, ovarian cancer and endometrial cancer. However, surgeons tend to prefer laparoscopy over laparotomy in cases of suspicious early-stage tumors according to the preoperative evaluation without fertile will. However, the surgical modality is ultimately determined by the surgeon after considering the surgeons' skill and the patients' characteristics. A retrospective analysis of all patients who underwent laparoscopic surgical management for gynecological cancer between May 2009 and May 2014 at the Guiyang Maternal Hospital was performed. According to the International Federation of Gynecology and Obstetrics (FIGO) guidelines, the optimal staging procedures for three types of cancer include hysterectomy, or radical hysterectomy, with or without bilateral salpingo-oophorectomy, with or without para-aortic lymphadenectomy, with or without omentectomy, and peritoneal cytology.

Laparotomy was performed in all cases via midline longitudinal incision by gynecologic specialists, according to our routine institutional practice as previously described [6]-[8]. In laparoscopic surgery, a 10-mm laparoscope was introduced at the umbilical site after pneumoperitoneum was established. Under direct vision, 3 ancillary trocars were positioned: one 12-mm suprapubic trocar for extraction of the retrieved lymph nodes and two 5-mm trocars at the lower abdomen lateral to the epigastric arteries. After employing this 4-trocar system, pelvic procedures were performed.

Surgical outcomes included surgical findings, operative time, estimated blood loss, and postoperative complications. Postoperative febrile morbidity was defined as a temperature of $\geq 38^{\circ} \mathrm{C}$. Urinary retention was defined as patients can not automatically discharge after removing the catheter.

Patients were allowed to drink water after they passed gas from the bowel, and thereafter, a liquid, soft, and normal regular diet was given on a daily basis until the patients had no complaints of gastrointestinal symptoms. Early ambulation was encouraged. In all patients, 3 kinds of antibiotics were used for at least 3 postoperative days; first- or second-generation cephalosporin was administered intravenously; and metronidazole, intravenously. 
Statistical analyses were performed by using the SPSS ver. 12.0 (SPSS Inc., Chicago, IL, USA) statistical software package. Data was described as ratio, median and range. Using the Kolmogorov-Smirnov test to determine whether the data showed a normal or not normal distribution, and differences between categorical variables in the two groups were analyzed by the chi-square test or Fisher's exact test. A $p$-value of $<0.05$ was considered statistically significant.

\section{Results}

Between May 2009 and May 2014, a total of 345 gynecological cancer patients presented with early-stage cancer (Figure 1). The characteristics of patients are shown in Table 1. The range of age was from 29 to 71 years, and 87 (25.22\%) were elderly (>60 years), 98 (28.41\%) were obese ( $\left.>30 \mathrm{~kg} / \mathrm{m}^{2}\right), 164$ (62.96\%) occurred menopause, $103(29.86 \%)$ had one previous abdominal surgery at least, $96(25 \%)$ had a history of medical disease (Table 1). Among the cases, patients of cervical cancer presented highest ratio on elderly age, high BMI, more previous abdominal surgery time, and more medical diseases.

The operative time and estimated blood loss were 3.5 hours (range, 2.5 - 5.5 hour) and $80 \mathrm{~mL}(20-200 \mathrm{~mL})$, respectively. Transfusion was required in 13 patients (3.77\%). and the transfusion amount were $280 \mathrm{~mL}$ (200 $400 \mathrm{~mL}$ ). The preoperative and postoperative hemoglobin level were $110 \mathrm{~g} / \mathrm{L}(65$ - $132 \mathrm{~g} / \mathrm{L})$ and $98 \mathrm{~g} / \mathrm{L}(78$ $125 \mathrm{~g} / \mathrm{L}$ ). The interval to bowel movement and indwelling catheter were 3 days (range, 1 - 5 days) and 7 days (range, 5 - 11 days). The median postoperative hospital stay was 10 days (range, 6 - 18 days) (Table 2).

Intra-operative complications occurred in 6 patients (1.74\%), and 34 patients (9.86\%) experienced postoperative complications (Table 3). The common intra-operative complications were bladder, ureter and bowel and vessel injury. After surgery, the most common adverse events included febrile morbidity, vesicovaginal fistula, urinary retention and poor wood healing. There were no cases of postoperative mortality, none of them required reoperation. After surgery, no one required intraoperative conversion to laparotomy.

In our department, we experienced laparoscopic surgery in 201 cases diagnosed with cervical cancer within five years. During the first stage (from May 2009 to May 2012), among the patients, the age of patients were beyond 60 years was occupied 15.63\% (15 cases). The body index was more than 30 in the first stage (3 cases; $3.12 \%)$ incline in the second stage (20; 19.05\%), which had statistical significance $(p<0.05)$.

The operative time was $4.27 \pm 0.23$ hours, estimated blood loss was $80 \mathrm{~mL}(20-200 \mathrm{~mL}$ ), and postoperative hospital stay was $10.36 \pm 2.56$ days. 20 patients were found surgical complications. When compared to the first stage, the operating time, estimated blood loss, hospital days ,operating time and peri-operative complications of cases decreased during the second stage (July 2012 to May 2014) $(p<0.05)$. Especially for the first three years, the complication rate higher than the cases in the second stage (Table 4).

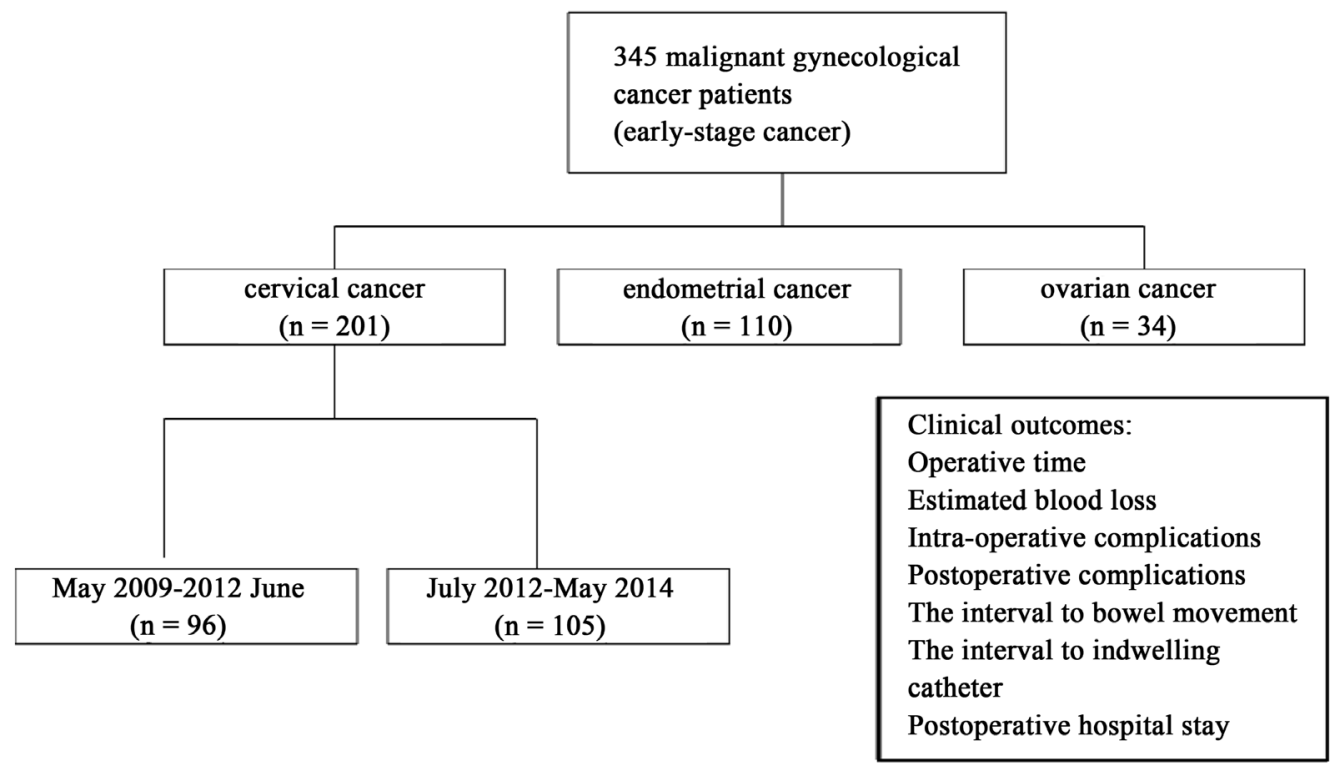

Figure 1. Schematic diagram of patients. 
Table 1. Characteristics of 345 patients in whom laparoscopic hysterectomy was attempted.

\begin{tabular}{|c|c|c|c|c|}
\hline & Cervical cancer & Endometrial cancer & Ovarian cancer & Total \\
\hline Cases (n) & 201 & 110 & 34 & 345 \\
\hline Age (range) & $48(29-71)$ & $42(32-65)$ & $51(41-67)$ & $48(29-71)$ \\
\hline$<60$ years, $\mathrm{n}(\%)$ & $146(72.63)$ & 89 (78.04) & $23(66.67)$ & $258(74.78)$ \\
\hline$>60$ years, $\mathrm{n}(\%)$ & 55 (27.37) & $21(21.95)$ & $11(33.3)$ & $87(25.22)$ \\
\hline \multicolumn{5}{|l|}{ Body mass index } \\
\hline BMI > 30, n (\%) & 75 (37.31) & $20(18.18)$ & $3(8.82)$ & $98(28.41)$ \\
\hline $\mathrm{BMI}<30, \mathrm{n}(\%)$ & $126(62.69)$ & $90(81.82)$ & 31 (91.18) & 347 (71.59) \\
\hline \multicolumn{5}{|l|}{ Menopause } \\
\hline Yes, n (\%) & $82(40.62)$ & 59 (53.65) & $23(66.67)$ & $164(62.96)$ \\
\hline No, n (\%) & $119(59.38)$ & $51(46.34)$ & $11(33.3)$ & $181(37.04)$ \\
\hline Previous abdominal surgery & $61(30.35)$ & 38 (34.55) & $4(11.76)$ & $103(29.86)$ \\
\hline No, 1 & $39(19.40)$ & 29 (26.36) & $3(8.82)$ & $71(20.58)$ \\
\hline 2 & $22(10.93)$ & $9(7.31)$ & $1(32.94)$ & $32(9.28)$ \\
\hline \multicolumn{5}{|l|}{ Comorbid medical disease } \\
\hline Yes, n (\%) & 35 (17.18) & 38 (34.15) & $23(66.67)$ & $96(25)$ \\
\hline No, n (\%) & $166(82.81)$ & 72 (65.85) & $11(33.3)$ & $249(75)$ \\
\hline
\end{tabular}

Values are presented as number (\%).

Table 2. Surgical outcomes of 345 patients in whom laparoscopic hysterectomy was attempted.

\begin{tabular}{lcccc}
\hline & Cervical cancer & Endometrial cancer & Ovarian cancer & Total \\
\hline \multicolumn{1}{c}{ Cases (n) } & 201 & 110 & 34 & 345 \\
Operative time median (range), hours & $3.5(2.5-5.5)$ & $3(3-5.5)$ & $2.5-4.6$ & $3.5(2.5-5.5)$ \\
Estimated blood loss median (range), mL & $80(20-200)$ & $100(20-200)$ & $80-100$ & $80(20-200)$ \\
Transfusion, n (\%) & $9(4.68)$ & $3(2.44)$ & $1(2.94)$ & $13(3.77)$ \\
Transfusion amount (range), mL & $280(200-400)$ & $400(200-400)$ & 200 & $280(200-400)$ \\
Preoperative hemoglobin level median (range), mL & $108(65-132)$ & $110(85-116)$ & $110(92-120)$ & $110(65-132)$ \\
Postoperative hemoglobin level median (range), mL & $98(78-125)$ & $100(83-123)$ & $100(90-110)$ & $98(78-125)$ \\
Time interval to bowel movement (range), day & $3(1-5)$ & $2(1-4)$ & $1-3$ & $3(1-5)$ \\
Time to indwelling catheter (range), day & $7(5-11)$ & $2(1-3)$ & $5-9$ & $7(5-11)$ \\
Postoperative hospital stay median (range), day & $10(6-18)$ & $8(7-16)$ & $9-14$ & $10(6-18)$ \\
\hline
\end{tabular}

Values are presented as number (range) or number (\%).

\section{Disscussion}

There have been many advances in minimally invasive surgical techniques. More studies reporting on the use of a laparoscopic surgery to perform gynecologic cancer, especially for malignant caner. Clinical studies have demonstrated that comparable oncologic outcomes can be obtained using laparoscopy compared to laparotomy while providing improved quality of life [9]-[11]. More gynecologists commonly employed laparoscopic hysterectomy in the management of gynecologic cancer for lower postoperative morbidity, pain, recovery time, operative time, and complications [12]-[14].

In recent years, technical advances in our center have allowed laparoscopic surgery was preferred for apparent early-stage gynecological cancer for minimal invasive. Laparoscopic hysterectomy (LH) was applied in our 
Table 3. Perioperative complications of 345 patients was attempted.

\begin{tabular}{ccccc}
\hline & Cervical cancer & Endometrial cancer & Ovarian cancer & Total \\
\hline Cases (n) & 201 & 110 & 34 & 345 \\
Intra-operative complications & $5(2.49)$ & $1(0.91)$ & 0 & $6(1.74)$ \\
Bladder injury & $1(0.50)$ & $1(0.91)$ & 0 & $2(0.58)$ \\
Ureter injury & $3(0.99)$ & 0 & 0 & $3(0.87)$ \\
Bowel injury & 0 & 0 & 0 & 0 \\
Vessel injury & $1(0.50)$ & 0 & 0 & $1(0.29)$ \\
Postoperative complications & $31(15.42)$ & $2(1.82)$ & $1(2.94)$ & $34(9.86)$ \\
Febrile morbidity & $1(0.50)$ & $1(0.91)$ & 0 & $3(0.87)$ \\
Vesicovaginal fistula & $3(1.49)$ & 0 & 0 & $1(0.87)$ \\
Brachial plexopathy & $1(0.50)$ & 0 & 0 & $1(0.29)$ \\
Inferior vena cava thrombosis & $1(0.50)$ & $1(0.91)$ & 0 & $23(6.67)$ \\
Urinary retention & $23(11.44)$ & 0 & 0 & $2(0.58)$ \\
\hline Abdominal incision poor healing & $2(0.99)$ & 0 & $0.29)$ \\
\hline
\end{tabular}

Values are presented as number (\%).

Table 4. Characteristics of cervical cancer cases during the 1st stage (2009-2012) and the 2th stage (2012-2014).

\begin{tabular}{cccc}
\hline Stage & May 2009-June 2012 & July 2012-May 2014 & Total \\
\hline Cases (n) & 96 & 105 & 201 \\
Age (years) & $48(29-71)$ & $50(31-71)$ & $48(29-71)$ \\
$<60$ years, n (\%) & $81(84.38)$ & $75(71.43)$ & $156(77.61)$ \\
$>$ 60 years, n (\%) & $15(15.63)$ & $30(28.57)$ & $45(22.39)$ \\
Body mass index & & & $23(11.44)$ \\
BMI > 30 (\%) & $3(3.12)$ & $20(19.05)^{*}$ & $178(88.56)$ \\
BMI <30 (\%) & $93(96.88)$ & $85(80.95)$ & $4.05 \pm 0.81$ \\
Operating time (hours) & $4.27 \pm 0.23$ & $3.81 \pm 0.84^{*}$ & $83.33 \pm 52.88$ \\
Blood loss (mL) & $100 \pm 61.80$ & $65 \pm 31.71^{*}$ & $9.23 \pm 1.76$ \\
Hospital days (day) & $10.36 \pm 2.56$ & $8.10 \pm 1.05^{*}$ & $36(17.91)$ \\
Complication, n (\%) & $24(25)$ & $12(11.43)^{*}$ & $5(2.49)$ \\
Inoperative complications, n (\%) & $4(4.17)$ & $1(0.95)^{*}$ & $5(2.49)$ \\
Organ injury, n (\%) & $4(4.17)$ & $1(0.95)$ & $31(15.42)$ \\
Postoperative complications, n (\%) & $20(20.83)$ & $11(10.48)^{*}$ & $23(11.44)$ \\
Urinary retention, n (\%) & $15(15.63)$ & $3(7.62)$ & $8(3.98)$
\end{tabular}

Values are presented as mean $\pm \mathrm{SD}$ or number $(\%) .{ }^{*} p<0.05$.

center include laparoscopic radical hysterectomy (LRH) and pure laparoscopic hysterectomy.

However, laparoscopic hysterectomy was usually applied in chosen cases, especially for the cases with younger age, lower body index, less surgical time, etc. In our series, all patients with early-stage cancer accordance with FIGO underwent LH, regardless of age, body mass index, and previous abdominal surgery. Surgical outcome reported that LH is feasible, and patient age and obesity may not be an absolute contraindication. In all patients in our department, none required conversion to laparotomy. And the result was similar to Jeong-Yeol 
Park's report [15]. However, our results also showed that more obesus and elder cervical cancer patients are prefer to laparoscopic surgery for increasing confidence. Meanwhile, we noted a low complication rate and excellent outcomes in our cases. Previous studies have also demonstrated the safety of LH. Less study was reported on the catalog of adverse events in LH cases. In our series, intra-operative complications occurred in 6 patients (1.74\%). 34 patients (9.86\%) experienced postoperative complications, and the injury of urinary system was the most common complication.

Current data demonstrated that postoperative complications occurred in 31 (15.42\%) in cervical cancer cases, urinary retention (11.44\%) and vesicovaginal fistula (1.49\%) were the most common complications. The highest occurrence was also found in cervical cancer cases, we postulated that higher occurrence related to wider incision range and higher possibility of nerve injury. Though laparoscopic radical hysterectomy (LRH) is now performed routinely around the world [16]. While this technique is less invasive than RH, it can still lead to substantial rates of postoperative complication for technical difficulty and the diversity of surgical techniques [17] [18].

Laparoscopic nerve-sparing radical hysterectomy (LNSRH) has been widely applied to operable cervical carcinoma since July 2012 in our center after standardized training. Many reports showed that the nerve-sparing approach is associated with lower postoperative morbidity. It may be a reliable technique for treating early cervical cancer. Thus, our study involves further analysis of the characteristics of cervical cancer patients during the first stage (2009-2012) and second stage (2012-2014). After June 2012, the operating time, estimated blood loss, decreased significantly in cervical cancer cases, and the results demonstrated that sufficient surgical experience and approach are both important in achieving optimal outcomes after LRH. Previous reporting showed that the disadvantage of LRH is its long learning curve. Several researchers have reported their learning curve for LRH [19]-[21]. Interestingly, we also found that adverse events decreased in cervical cancer cases during the second stage in past five years. Sufficient surgical experience and surgical training can improve optimal outcomes, and the conclusion was same to many reports [15].

Nevertheless, there were some methodological limitations of the study. Firstly, the retrospective nature of the present study did not allow us to evaluate the function of bladder and sex, especially for the evaluation of postoperative life quality. Moreover, analysis of tumor size, uterus volume, blood supply and MRI imaging were not conducted due to minimal cases. Thus, a further prospective study with a larger study is needed to confirm the utility of laparoscopic surgical management of apparent early-stage gynecological cancer.

\section{Conclusion}

In conclusion, our data suggest that comparable outcomes can be obtained using laparoscopy applied for earlystage gynecological cancer. In our center, laparoscopic surgery may be a suitable approach for unselected cases, such as elderly, obesity and those with history of previous abdominal surgery. Meanwhile, we found the highest complication rate in LRH cases, and it decreased with surgical skill improved. Thus, LRH by experienced surgeons could gain comparable feasibility and effectiveness.

\section{References}

[1] Gowri, V., Koliyadan, S.V., Al Hamdani, A. and Al Kindy, N. (2012) Successful Term Pregnancies after Laparoscopic Excision of Poorly Differentiated Sertoli Leydig Cell Tumor of the Ovary. Journal of Gynecologic Oncology, 23, 201204. http://dx.doi.org/10.3802/jgo.2012.23.3.201

[2] Koo, Y.J., Kim, J.E., Kim, Y.H., Hahn, H.S., Lee, I.H., Kim, T.J., Lee, K.H., Shim, J.U. and Lim, K.T. (2014) Comparison of Laparoscopy and Laparotomy for the Management of Early-Stage Ovarian Cancer: Surgical and Oncological Outcomes. Journal of Gynecologic Oncology, 25, 111-117. http://dx.doi.org/10.3802/jgo.2014.25.2.111

[3] Yoon, A., Kim, T.J., Lee, W.S., Kim, B.G. and Bae, D.S. (2011) Single-Port Access Laparoscopic Staging Operation for a Borderline Ovarian Tumor. Journal of Gynecologic Oncology, 22, 127-130. http://dx.doi.org/10.3802/jgo.2011.22.2.127

[4] Nam, J.H., Park, J.Y., Kim, D.Y., Kim, J.H., Kim, Y.M. and Kim, Y.T. (2012) Laparoscopic versus Open Radical Hysterectomy in Early-Stage Cervical Cancer: Long-Term Survival Outcomes in a Matched Cohort Study. Annals of Oncology, 23, 903-911. http://dx.doi.org/10.1093/annonc/mdr360

[5] Nezhat, F.R., Ezzati, M., Chuang, L., Shamshirsaz, A.A., Rahaman, J. and Gretz, H. (2009) Laparoscopic Management of Early Ovarian and Fallopian Tube Cancers: Surgical and Survival Outcome. American Journal of Obstetrics and Gynecology, 200, 1-6. http://dx.doi.org/10.1016/j.ajog.2008.08.013 
[6] Nam, J.H., Kim, J.H. and Kim, D.Y. (2004) Comparative Study of Laparoscopico Vaginal Radical Hysterectomy and Abdominal Radical Hysterectomy in Patients with Early Cervical Cancer. Gynecologic Oncology, 92, 277-283. http://dx.doi.org/10.1016/j.ygyno.2003.09.003

[7] Park, J.Y., Kim, D.Y. and Kim, J.H. (2012) Laparoscopic versus Open Radical Hysterectomy for Elderly Patients with Early-Stage Cervical Cancer. American Journal of Obstetrics and Gynecology, 207, 1-8. http://dx.doi.org/10.1016/j.ajog.2012.06.081

[8] Park, J.Y., Kim, D.Y. and Kim, J.H. (2012) Laparoscopic Compared with Open Radical Hysterectomy in Obese Women with Early-Stage Cervical Cancer. Gynecologic Oncology, 119, 1201-1209.

[9] Eltabbakh, G.H., Shamonki, M.I., Moody, J.M. and Garafano, L.L. (2001) Laparoscopy as the Primary Modality for the Treatment of Women with Endometrial Carcinoma. Cancer, 91, 378-387. http://dx.doi.org/10.1002/1097-0142(20010115)91:2<378::AID-CNCR1012>3.0.CO;2-F

[10] Nezhat, F.R., Ezzati, M., Chuang, L., Shamshirsaz, A.A., Rahaman, J. and Gretz, H. (2009) Laparoscopic Management of Early Ovarian and Fallopian Tube Cancers: Surgical and Survival Outcome. American Journal of Obstetrics and Gynecology, 200, 1-6. http://dx.doi.org/10.1016/j.ajog.2008.08.013

[11] Medeiros, L.R., Rosa, D.D., Bozzetti, M.C., Rosa, M.I., Edelweiss, M.I., Stein, A.T., Zelmanowicz, A., Ethur, A.B. and Zanini, R.R. (2008) Laparoscopy versus Laparotomy for FIGO Stage I Ovarian Cancer. Cochrane Database of Systematic Reviews, 4, Article ID: CD005344.

[12] Walker, J.L., Piedmonte, M.R., Spirtos, N.M., Eisenkop, S.M., Schlaerth, J.B., Mannel, R.S., et al. (2012) Recurrence and Survival after Random Assignment to Laparoscopy versus Laparotomy for Comprehensive Surgical Staging of Uterine Cancer: Gynecologic Oncology Group LAP2 Study. Journal of Clinical Oncology, 30, 695-700. http://dx.doi.org/10.1200/JCO.2011.38.8645

[13] Koo, Y.J., Kim, J.E., Kim, Y.H., Hahn, H.S., Lee, I.H., Kim, T.J., Lee, K.H., Shim, J.U. and Lim, K.T. (2014) Comparison of Laparoscopy and Laparotomy for the Management of Early-Stage Ovarian Cancer: Surgical and Oncological Outcomes. Journal of Gynecologic Oncology, 25, 111-117. http://dx.doi.org/10.3802/jgo.2014.25.2.111

[14] Einarsson, J.I., Matteson, K.A., Schulkin, J., Chavan, N.R. and Sangi-Haghpeykar, H. (2010) Minimally Invasive Hysterectomies-A Survey on Attitudes and Barriers among Practicing Gynecologists. Journal of Minimally Invasive Gynecology, 17, 167-175. http://dx.doi.org/10.1016/j.jmig.2009.12.017

[15] Park, J.Y. and Nam, J.H. (2014) Laparotomy Conversion Rate of Laparoscopic Radical Hysterectomy for Early-Stage Cervical Cancer in a Consecutive Series without Case Selection. Annals of Surgical Oncology, 21, 3030-3035. http://dx.doi.org/10.1245/s10434-014-3707-5

[16] Puntambekar, S.P., Palep, R.J., Puntambekar, S.S., Wagh, G.N., Patil, A.M., et al. (2007) Laparoscopic Total Radical Hysterectomy by the Technique: Our Experience of 248 Cases. Journal of Minimally Invasive Gynecology, 14, 682689. http://dx.doi.org/10.1016/j.jmig.2007.05.007

[17] Pellegrino, A., Signorelli, M., Fruscio, R., Villa, A., Buda, A., Beretta, P., Garbi, A. and Vitobello, D. (2009) Feasibility and Morbidity of Total Laparoscopic Radical Hysterectomy with or without Pelvic Limphadenectomy in Obese Women with Stage I Endometrial Cancer. Archives of Gynecology and Obstetrics, 279, 655-660. http://dx.doi.org/10.1007/s00404-008-0790-5

[18] Pomel, C., Atallah, D., Le Bouedec, G., Rouzier, R., Morice, P., Castaigne, D. and Dauplat, J. (2003) Laparoscopic Radical Hysterectomy for Invasive Cervical Cancer: 8-Year Experience of a Pilot Study. Gynecologic Oncology, 91, 534-539. http://dx.doi.org/10.1016/j.ygyno.2003.08.035

[19] Hwang, J.H., Yoo, H.J., Joo, J., Kim, S., Lim, M.C., Song, Y.J. and Park, S.Y. (2012) Learning Curve Analysis of Laparoscopic Radical Hysterectomy and Lymph Node Dissection in Early Cervical Cancer. European Journal of Obstetrics and Gynecology and Reproductive Biology, 163, 219-223. http://dx.doi.org/10.1016/j.ejogrb.2012.05.005

[20] Reade, C., Hauspy, J., Schmuck, M.L. and Moens, F. (2011) Characterizing the Learning Curve for Laparoscopic Radical Hysterectomy: Buddy Operating as a Technique for Accelerating Skill Acquisition. International Journal of Gynecological Cancer, 21, 930-935. http://dx.doi.org/10.1097/IGC.0b013e3182157a44

[21] Chong, G.O., Park, N.Y., Hong, D.G., Cho, Y.L., Park, I.S. and Lee, Y.S. (2009) Learning Curve of Laparoscopic Radical Hysterectomy with Pelvic and/or Para-Aortic Lymphadenectomy in the Early and Locally Advanced Cervical Cancer: Comparison of the First 50 and Second 50 Cases. International Journal of Gynecological Cancer, 19, 14591464. http://dx.doi.org/10.1111/IGC.0b013e3181b76640 
Scientific Research Publishing (SCIRP) is one of the largest Open Access journal publishers. It is currently publishing more than 200 open access, online, peer-reviewed journals covering a wide range of academic disciplines. SCIRP serves the worldwide academic communities and contributes to the progress and application of science with its publication.

Other selected journals from SCIRP are listed as below. Submit your manuscript to us via either submit@scirp.org or Online Submission Portal.
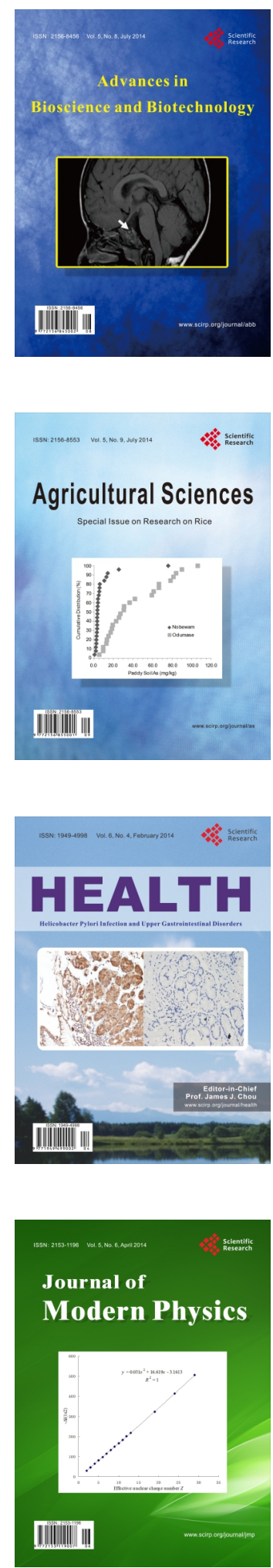
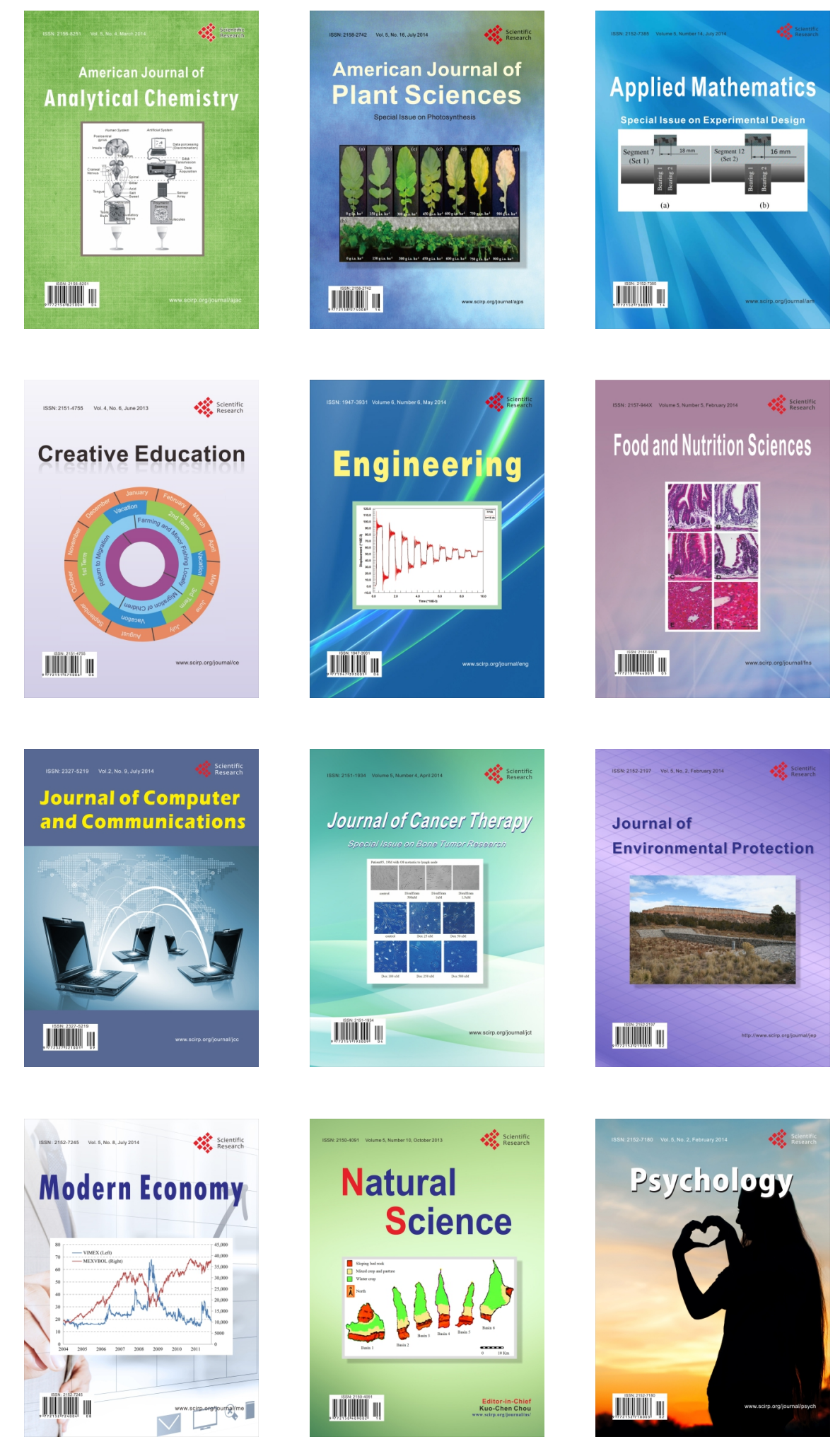